\title{
Tourette syndrome and learning disabilities
}

\section{Larry Burd ${ }^{* \dagger 1}$, Roger D Freeman ${ }^{\dagger 2}$, Marilyn G Klug ${ }^{\dagger 1}$ and Jacob Kerbeshian ${ }^{\dagger 3}$} \begin{abstract}
North Dakota School of Medicine and Health Sciences, Grand Forks, North Dakota, USA
Email: Larry Burd* - laburd@medicine.nodak.edu; Roger D Freeman - roger_freeman@yahoo.com; Marilyn G Klug - marilyn_klug@und.nodak.edu; Jacob Kerbeshian - jkerbesh@medicine.nodak.edu

* Corresponding author †Equal contributors
\end{abstract}

Address: ${ }^{1}$ Department of Pediatrics, University of North Dakota School of Medicine and Health Sciences, Grand Forks, North Dakota, USA, ${ }^{2}$ Department of Pediatrics, University of British Columbia, Vancouver, British Columbia, Canada and ${ }^{3}$ Department of Neuroscience, University of

Published: 0 I September 2005

BMC Pediatrics 2005, 5:34 doi:10.1186/147|-2431-5-34
Received: 13 December 2004

Accepted: 0 I September 2005

This article is available from: http://www.biomedcentral.com/I47I-243I/5/34

(C) 2005 Burd et al; licensee BioMed Central Ltd.

This is an Open Access article distributed under the terms of the Creative Commons Attribution License (http://creativecommons.org/licenses/by/2.0), which permits unrestricted use, distribution, and reproduction in any medium, provided the original work is properly cited.

\begin{abstract}
Background: Tourette Syndrome (TS) is a neurodevelopmental disorder of childhood. Learning disabilities are frequently comorbid with TS. Using the largest sample of TS patients ever reported, we sought to identify differences between subjects with TS only and subjects with TS and a comorbid learning disability.
\end{abstract}

Methods: We used the Tourette Syndrome International Consortium database (TIC) to compare subjects with comorbid Tourette Syndrome and learning disabilities (TS + LD) to subjects who did not have a comorbid learning disability (TS - LD). The TIC database contained 5,500 subjects. We had usable data on 5,450 subjects.

Results: We found I,235 subjects with TS + LD. Significant differences between the TS + LD group and the TS - LD group were found for gender (.00I), age onset (.030), age first seen (.00I), age at diagnosis $(.00 \mathrm{I})$, prenatal problems $(.00 \mathrm{I})$, sibling or other family member with tics $(.024)$, two or more affected family members (.009), and severe tics (.046). We used logistic modeling to identify the optimal prediction model of group membership. This resulted in a five variable model with the epidemiologic performance characteristics of accuracy $65.2 \%$ (model correctly classified 4,406 of 5,450 subjects), sensitivity $66.1 \%$, and specificity $62.2 \%$.

Conclusion: Subjects with TS have high prevalence rates of comorbid learning disabilities. We identified phenotype differences between the TS - LD group compared to TS + LD group. In the evaluation of subjects with TS, the presence of a learning disability should always be a consideration. ADHD may be an important comorbid condition in the diagnosis of LD or may also be a potential confounder. Further research on etiology, course and response to intervention for subjects with TS only and TS with learning disabilities is needed.

\section{Background}

Tourette Syndrome (TS) is a complex developmental disorder defined by the childhood onset of motor and vocal tics with a longitudinal outcome of gradual improvement in most subjects [1-4]. The disorder is associated with increased prevalence rates of comorbid disorders, the most common of which is attention-deficit hyperactivity disorder (ADHD) [5,6]. Learning disabilities (LD) and obsessive-compulsive disorder (OCD) or obsessive and compulsive behaviors (OCB) are also common [7-10]. 
In previous work we have demonstrated that over time the presence of comorbidity is an important factor in syndromal severity and in the level of impairment from the disorder [11]. While several disorders have been demonstrated to occur as a manifestation of the broad TS phenotype (OCD, ADHD) the role of several other conditions is currently a contentious issue in the definition of that broad phenotype $[8-10,12]$. Previous research has demonstrated increased prevalence of LD in subjects with TS but the role of LD as a manifestation of the broad TS phenotype is not yet settled $[8,10,13-25]$.

Previous research on TS and comorbid LD has relied on relatively small samples usually selected from 1 or 2 clinic sites [13-20,22-26]. The limitations of small sample size and selected catchments for these studies have led to concerns about the generalizability of the results of these studies. In order to minimize these limitations, we have elected to utilize a large international population of cases of TS and TS with comorbid LD to examine differences in subjects with TS without a comorbid learning disability and subjects with TS and a comorbid learning disability. We utilized data from the Tourette Syndrome International Consortium (TIC) to examine differences between subjects with Tourette Syndrome and learning disabilities (TS + LD) and subjects with Tourette Syndrome who did not have a comorbid learning disability (TS - LD). We have utilized data from this consortium for multiple other studies of TS including comorbid TS and pervasive developmental disorders, prediction of tic severity, and hereditary factors in tic severity [27].

\section{Methods}

The study population was comprised of consecutive subjects entered into the database since its inception. The 5,500 subjects in this study include the 3,500 subjects previously reported in the paper by Freeman and colleagues [28].

\section{Registry reporting sites}

Thirty-six sites have over 50 subjects and seventeen sites have over 100 subjects. Twenty-four sites have less than 50 cases and 19 are currently inactive. The geographic distribution of the consortium cases was: Canada $40.6 \%$, United States 22.6\%, Europe 25.1\%, Middle East 3.6\%, South America 1.8\%, Asia 3.0\%, Australia 3.0\%, and Africa $0.3 \%$. The clinicians who submit cases to the registry are either physicians (nearly all) or psychologists.

\section{Subject selection}

All subjects entered in the registry met the criteria for TS from the Tourette Syndrome Classification Study Group [29]. Each subject was reported utilizing a structured reporting format [see Additional file 1] to assure comparability of the data. A learning disabilities diagnosis entered into the registry was inclusive of specific learning disorders as defined in the DSM-IV, through the less precise and less verifiable category of learning disorders NOS [30]. The diagnosis of LD would only rarely include individuals with mental retardation (MR). In this paper we excluded the few subjects with both LD and MR. The TIC database does not have data on the proportion of subjects diagnosed with LD after psychometric testing or the proportion where LD was a clinical diagnosis or both.

Subject data were then forwarded to the consortium where each case was reviewed for inconsistencies prior to entry into the database. If errors were identified or suspected, the case file was returned to the clinical site for review. This data is not verified beyond the identification of errors in either data entry from the submitted form (data entry control procedures are utilized to minimize these errors) or unless an error is detectable by the field entry restriction values for each variable.

We utilized the method of Spady et al. for management of summary data [31]. As in most reported cohorts we were not able to detect diagnostic error. To minimize the potential impact of errors we do not report values from individual clinical sites. Thus, the results represent pooled data from multiple sites to reduce any potential impact from systematic or inadvertent error from any one site. This data pooling increases accuracy but does so by obscuring between site differences and as a result decreases precision.

\section{Statistical analysis}

For this study we had usable data on 5,450 subjects. Continuity corrected Chi-Square was used to test the association between gender, age of onset, age first seen, age diagnosed, clinician type, perinatal problems, heredity of TS, severity of TS, and fourteen comorbidities by group (TS + LD) and (TS - LD). Since LD was used to define one of the groups in this study LD was not counted as a comorbid disorder in the study. Thus, the variable comorbidity is comprised of all other comorbid disorders available from the dataset. Observations with missing values were deleted for each univariate analysis. After completion of the univariate analysis, we used logistic regression modeling to identify the optimal set of prediction variables to predict group membership TS + LD. We used the epidemiologic performance characteristics of accuracy, sensitivity and specificity to select a final logistic model.

\section{Results}

Of the 5,450 subjects with TS, the TS + LD group was comprised of 1,235 subjects $(22.7 \%)$ while the TS - LD group had 4,215 (76.3\%) subjects. In the TS - LD group, 3,774 subjects (69.2\%) had other comorbid conditions. Four hundred and forty-one patients of the TS-LD group 
Table I: Between group comparisons in $\mathbf{5 , 4 5 0}$ subjects with Tourette Syndrome and Learning Disabilities (TS + LD) and Tourette Syndrome without learning disabilities(TS-LD) by gender, age, perinatal problems, and family history of tics.

\begin{tabular}{|c|c|c|c|c|c|}
\hline & \multicolumn{2}{|c|}{$\mathrm{TS}+\mathrm{LD}$} & \multicolumn{2}{|c|}{ TS - LD } & \multirow[b]{2}{*}{$P$} \\
\hline & $\mathrm{n}$ & (\%) & $\mathrm{n}$ & (\%) & \\
\hline \multicolumn{6}{|l|}{ Gender } \\
\hline Female & 159 & $(12.9)$ & 857 & $(20.3)$ & $<.001$ \\
\hline Male & 1,076 & (87.1) & 3,355 & (79.7) & \\
\hline \multicolumn{6}{|c|}{ Age of Onset of TS } \\
\hline$<=4$ & 261 & $(25.1)$ & 922 & $(24.8)$ & .030 \\
\hline 5 to 7 & 517 & $(49.7)$ & 1,709 & $(45.9)$ & \\
\hline 8 or Older & 263 & $(25.3)$ & 1,089 & $(29.3)$ & \\
\hline \multicolumn{6}{|l|}{ Age First Seen } \\
\hline$<=17$ & $|, 07|$ & $(87.4)$ & 3,118 & $(74.6)$ & $<.001$ \\
\hline$>17$ & 154 & $(12.6)$ & 1,063 & $(25.4)$ & \\
\hline \multicolumn{6}{|l|}{ Age Diagnosed } \\
\hline$<=8$ & 416 & (35.8) & 1,275 & (32.5) & $<.001$ \\
\hline 9 to 12 & 488 & $(42.0)$ & 1,366 & (34.8) & \\
\hline 13 or Older & 257 & $(22.1)$ & 1,284 & $(32.7)$ & \\
\hline \multicolumn{6}{|c|}{ Perinatal Problems } \\
\hline Yes & 280 & $(26.9)$ & 607 & $(17.1)$ & $<.001$ \\
\hline No & 761 & (73.1) & 2,945 & (82.9) & \\
\hline \multicolumn{6}{|c|}{ Has a Child with Tics } \\
\hline Yes & 12 & $(1.0)$ & 104 & $(2.6)$ & .002 \\
\hline No & 1,189 & $(99.0)$ & 3,913 & $(97.4)$ & \\
\hline \multicolumn{6}{|c|}{ At Least One Family Member with Tics } \\
\hline Yes & 613 & $(51.0)$ & 2,201 & $(54.8)$ & .024 \\
\hline No & 588 & $(49.0)$ & 1,816 & $(45.2)$ & \\
\hline \multicolumn{6}{|c|}{ Two or More Family Members with Tics } \\
\hline Yes & 145 & $(12.1)$ & 609 & $(15.2)$ & .009 \\
\hline No & 1,056 & $(87.9)$ & 3,408 & $(84.8)$ & \\
\hline \multicolumn{6}{|l|}{ Has Severe Tics } \\
\hline Yes & 226 & $(18.3)$ & 668 & $(15.9)$ & .046 \\
\hline No & 1,009 & $(81.7)$ & 3,544 & $(84.1)$ & \\
\hline
\end{tabular}

Missing data alters the row and column totals for some variables.

$(8.1 \%)$ had no comorbid disorders or conditions. In the TS + LD group the average number of comorbidities other than LD was 3.04 (s.d. 2.07). The analysis includes all the variables included in the database. The average age of onset of TS was 6.37 years (s.d. $=2.82)$ and was determined by parental report of tic onset. The average age of diagnosis was 13.43 years (s.d. $=10.0$ ). The TIC Registry population was $81.4 \%$ male, while $19.3 \%$ had perinatal problems and $53.9 \%$ had at least one family member with a history of tics or TS.

Table 1 shows variables with significant associations for TS + LD. Subjects with TS + LD had an increased proportion of males $(\mathrm{p}<.001)$, and have an age of onset of TS before eight years of age $(p=.030)$. They also were first seen before 18 years of age $(\mathrm{p}<.001)$ and were diagnosed before they were thirteen years of age $(p<.001)$. The average age of onset for those with TS + LD was 6.14 (s.d. = 2.56 ) and was comparable to 6.44 years (s.d. $=2.88$ ) for those with TS - LD. The average age first seen for those with TS + LD was 12.5 (s.d. = 7.5), while it was over three years later $($ mean $=15.7$, s.d. $=11.6)$ for those with TS $\mathrm{LD}$. The average age for diagnosis in TS + LD was also three years earlier $($ mean $=11.4$, s.d. $=7.1)$ compared to those with TS - LD $($ mean $=14.0$, s.d. $=10.6)$. Seventy-four percent of the cases were diagnosed by a psychiatrist and 19\% were diagnosed by a neurologist $(\mathrm{p}<.001)$.

Perinatal problems were prevalent in 27 percent of those with TS + LD, and only 17 percent for those with TS - LD $(p<.001)$. The proportion of subjects with TS + LD were somewhat less likely to have a child with tics $(\mathrm{p}=.02)$ or have at least one family member with tics or TS (12 percent) when compared to the proportion of subjects with TS - LD (15 percent, $\mathrm{p}=.009$ ). The proportion of subjects with severe tics in the TS + LD group was only slightly higher $(18 \%)$ compared to those with TS - LD (16\%), p = .046 . 
Table 2: Between group comparisons in 5,450 people with Tourette Syndrome and comorbid learning disabilities (TS + LD) and Tourette Syndrome without learning disabilities (TS - LD).

\begin{tabular}{|c|c|c|c|c|c|}
\hline & & & & & \\
\hline & $\mathrm{n}$ & (\%) & $\mathrm{n}$ & $\%$ & $P$ \\
\hline ADHD & 990 & $(80.2)$ & 2,161 & $(5 \mid .3)$ & $<.001$ \\
\hline Anger & 570 & $(46.2)$ & $\mathrm{I}, 424$ & $(33.8)$ & $<.001$ \\
\hline Sleep & 372 & $(30.2)$ & 998 & (23.7) & $<.001$ \\
\hline Mood & 266 & $(21.5)$ & 767 & $(18.2)$ & $<.001$ \\
\hline Social Skills & 409 & (33.1) & 620 & $(14.7)$ & $<.001$ \\
\hline Anxiety & 249 & $(20.2)$ & 686 & $(16.3)$ & .002 \\
\hline Sexual Behavior & 85 & $(8.1)$ & 137 & $(4.0)$ & $<.001$ \\
\hline$C D$ & 250 & $(20.2)$ & 504 & $(12.0)$ & $<.001$ \\
\hline Coprolalia & 199 & $(16.1)$ & 531 & $(12.6)$ & .002 \\
\hline Stutter & 137 & (II.I) & 271 & $(6.4)$ & $<.001$ \\
\hline Neurologic & 104 & $(8.4)$ & 218 & $(5.2)$ & $<.001$ \\
\hline DevD & 137 & (II.I) & 180 & $(4.3)$ & $<.001$ \\
\hline PDD & 101 & $(8.18)$ & 167 & $(4.0)$ & $<.001$ \\
\hline Psy & 20 & $(1.6)^{\prime}$ & 37 & $(0.9)$ & .037 \\
\hline
\end{tabular}

Attention deficit-hyperactivity disorder (ADHD), conduct disorder (CD), obsessive compulsive disorder (OCD), obsessive compulsive behavior (OCB), developmental disorder (DevD), learning disability (LD), mental retardation (MR), pervasive developmental disorder (PDD), psychosis (Psy) and neurological abnormality (Neurologic).

Subjects with TS + LD were more likely to have one or more of the fourteen comorbid disorders and conditions in the dataset when compared to those subjects with TS LD (Table 2). Increases in comorbid conditions ranged from 0.7 percent for (psychotic disorder, $\mathrm{p}=.037$ ) to 28.9 percent for (ADHD, $\mathrm{p}<.001)$. The mean number of comorbidities for subjects with TS + LD was 3.9 (s.d. = 2.2) and for subjects with TS - LD was 2.8 (s.d. = 2.0).

ADHD was the most prevalent comorbid disorder for subjects with TS + LD. In this population, 58\% (3151) of the TS children had ADHD and 31\% (990) of these had LD. The potential impact of ADHD on LD either as a causal factor or as a confounder for the diagnosis of LD is demonstrated by the finding that only $11 \%$ (245) of the 2299 TS children without ADHD had LD.

The variables from Table 1 and the total number of comorbidities were entered into a logistic regression model. The optimal prediction model for the TS + LD group was comprised of five variables (being seen for evaluation before 18, being male, having fewer family members with tics or TS, having perinatal problems, and having more comorbidities). The logistic model performance characteristics were accuracy $65.2 \%$ (model correctly classified 4,406 of 5,450 subjects), sensitivity $66.1 \%$ and specificity of $62.2 \%$.

\section{Discussion}

In a population of 5,450 subjects with TS, we found 1,235 subjects with comorbid LD (TS + LD). Using logistic regression, we produced a five variable model that accurately predicted group membership for $65.2 \%$ of the 5,450 subjects in this study. The model parameters were male gender, fewer affected family members, increased rates of pregnancy, labor and delivery complications, increased prevalence of comorbidities and younger age at diagnosis. The absolute differences in rates of comorbidities between the groups for individual variables were often small and as a result the differences may be of limited clinical relevance. However, the five variable model may well have relevance for risk assessment for clinicians caring for subjects with TS and possibly for healthcare policy makers as well. Confirmation of our estimates of the performance characteristics of this model as a screening tool would require further study in a clinical setting. However, the development of a screening tool would be beneficial since delayed identification of learning disabilities results in delayed initiation of intervention services and likely increases the educational difficulty experienced by a person with an unidentified learning disability [22, 32].

The etiology of learning disabilities and the appropriate conceptual view of these diverse disorders as comorbid disorders or as variably prevalent components of the broader TS phenotype has yet to be resolved [3, 9, 10, 14, $15,33]$. In this study, ADHD was the most prevalent comorbid disorder with TS occurring in $57.8 \%$ of subjects $(\mathrm{n}=3151)$. In subjects with TS + LD, 80.2\% also had a diagnosis of ADHD and in the TS - LD group, 51.3\% had a diagnosis of ADHD. We found that $31 \%$ of subjects with ADHD also had a diagnosis of LD compared to only $11 \%$ 
in subjects with TS who did not have ADHD. Thus, the comorbidity rates in this study may not differ from those reported for ADHD and reading disorders alone [34, 35]. where the prevalence of comorbidity between reading disorders and ADHD is 25 to $40 \%$. The increased rates of ADHD in the TS + LD group may have multiple explanations including the possibility that ADHD is a confounder and that most cases of LD in subjects with TS represent the additional impairments in learning from the ADHD. In which case LD is misdiagnosed or that ADHD is an important component in the causal chain for LD and that LD is very often under diagnosed in subjects with ADHD. Additional research is required to determine which, if either, of these possibilities is correct. Other data sets will likely be required to examine the role of $\mathrm{ADHD}$ on $\mathrm{LD}$ in subjects with TS and other combinations of LD, ADHD and TS.

\section{Limitations}

We have defined the two groups used in this study by the presence or absence of a clinically defined learning disability. We are unable to determine the accuracy of the diagnosis for subjects in this study. In this study we did not have the data to restrict LD cases to a single set of criteria. For example, we did not count only cases meeting the discrepancy criteria, which is a widely used strategy for the diagnosis of LD in the United States. We are not aware of a single diagnostic schema with wider acceptance around the world than the DSM criteria. As a result the prevalence estimates in this study may be biased. This might alter the accuracy of prevalence estimates or the significance testing for some variables. However, given the effect sizes found here, the bias would have to be consistent and quite large to alter the primary results.

\section{Conclusion}

We found the prevalence of LD to be increased in subjects with TS. Additional studies are required to improve our understanding of the etiologic factors resulting in the expression of the patterns of individual syndromal variability noted in this and in other studies. It would be of interest to examine hypotheses to determine if subjects with TS have different types of LD or have specific patterns of comorbidity with LD. However, developing test batteries for subjects from over 20 different languages, cultures and differing academic systems seems a formidable task.

Improved understanding of the factors associated with a later diagnosis of an LD may have important implications for prevention of secondary disabilities especially those which result from symptom expression prior to a diagnosis of either TS or of TS with comorbidity $[22,36]$. This recognition may be years or in some cases decades delayed. Ongoing research is needed to identify appropriate medical, psychosocial or educational management strategies for the two broad groups discussed here in this paper.

\section{Competing interests}

The author(s) declare that they have no competing interest.

\section{Authors' contributions}

$\mathrm{RF}, \mathrm{LB}$, and JK designed the study, and RF developed and maintained the TIC Registry. MK completed the data analysis. RF, LB, MK and JK wrote the manuscript and contributed important intellectual content. All authors have read and approved the final manuscript.

\section{Additional material}

\section{Additional File 1}

TIC Data Entry Form. The TIC Consortium Data Entry Form is a standardized form used by each center to extract data elements from the record for submission to the consortium database.

Click here for file

[http://www.biomedcentral.com/content/supplementary/14712431-5-34-S1.doc]

\section{References}

I. Bruun RD, Budman CL: The course and prognosis of Tourette syndrome. Neurol Clin 1997, I 5:291-298.

2. Burd L, Kerbeshian J, Barth A, Klug MG, Avery PK, Benz B: Longterm follow-up of an epidemiologically defined cohort of patients with Tourette syndrome. J Child Neurol 2001, 16:431-437.

3. Leckman JF, Zhang H, Vitale A, Lahnin F, Lynch K, Bondi C, Kim YS, Peterson BS: Course of tic severity in Tourette syndrome: the first two decades. Pediatrics 1998, I02:14-19.

4. American Psychiatric Association: Diagnostic and statistical manual of mental disorders DSM-IV-TR. text revision 4th edition. Washington, DC: American Psychiatric Association; 2000.

5. Kerbeshian J, Burd L: Epidemiology and comorbidity. The North Dakota prevalence studies of Tourette syndrome and other developmental disorders. Adv Neurol 1992, 58:67-74.

6. Freeman RD, Fast DK, Burd L, Kerbeshian J, Robertson MM, Sandor $P$ : An international perspective on Tourette syndrome: selected findings from 3,500 individuals in 22 countries. Dev Med Child Neurol 2000, 42:436-447.

7. Comings DE, Comings BG: TS, learning, and speech problems. J Am Acad Child Adolesc Psychiatry 1994, 33:429-430.

8. Pauls DL, Leckman JF, Cohen DJ: Familial relationship between Gilles de la Tourette's syndrome, attention deficit disorder, learning disabilities, speech disorders, and stuttering. J Am Acad Child Adolesc Psychiatry 1993, 32:1044-1050.

9. Comings DE, Comings BG: A controlled study of Tourette syndrome. I. Attention-deficit disorder, learning disorders, and school problems. Am J Hum Genet 1987, 4I:70I-74I.

10. Como PG: Neuropsychological function in Tourette syndrome. Adv Neurol 2001, 85:103-III.

II. Casey MB, Cohen M, Schuerholz LJ, Singer HS, Denckla MB: Language-based cognitive functioning in parents of offspring with ADHD comorbid for Tourette syndrome or learning disabilities. Dev Neuropsychol 2000, I 7:85-I 10.

12. Comings DE, Gade-Andavolu R, Gonzalez N, Blake H, Wu S, MacMurray JP: Additive effect of three noradrenergic genes (ADRA2a, ADRA2C, DBH) on attention-deficit hyperactivity disorder and learning disabilities in Tourette syndrome subjects. Clin Genet 1999, 55:160-172. 
13. Yeates KO, Bornstein RA: Neuropsychological correlates of learning disability subtypes in children with Tourette's syndrome. J Int Neuropsychol Soc 1996, 2:375-382.

14. Eapen V, Robertson MM, Zeitlin H, Kurlan R: Gilles de la Tourette's syndrome in special education schools: a United Kingdom study. J Neurol 1997, 244:378-382.

15. Walkup JT, Scahill LD, Riddle MA: Disruptive behavior, hyperactivity, and learning disabilities in children with Tourette's syndrome. Adv Neurol 1995, 65:259-272.

16. Singer HS, Schuerholz LJ, Denckla MB: Learning difficulties in children with Tourette syndrome. J Child Neurol 1995, IO(Suppl I):S58-S6I.

17. Brookshire BL, Butler IJ, Ewing-Cobbs L, Fletcher JM: Neuropsychological characteristics of children with Tourette syndrome: evidence for a nonverbal learning disability? J Clin Exp Neuropsychol 1994, 16:289-302.

18. Burd L, Kauffman DW, Kerbeshian J: Tourette syndrome and learning disabilities. J Learn Disabil 1992, 25:598-604.

19. Burd L, Kerbeshian J: Educational management of children with Tourette syndrome. Adv Neurol 1992, 58:3 I I-317.

20. Comings DE, Comings BG: A controlled family history study of Tourette's syndrome, I: Attention-deficit hyperactivity disorder and learning disorders. J Clin Psychiatry 1990, 5 I:275-280.

21. Matthews WS: Attention deficits and learning disabilities in children with Tourette's syndrome. Pediatr Ann 1988, I 7:4 I0-I. $4|4,4| 6$

22. Lerer RJ: Motor tics, Tourette syndrome, and learning disabilities. J Learn Disabil 1987, 20:266-267.

23. Definitions and classification of tic disorders. The Tourette Syndrome Classification Study Group. Arch Neurol 1993, 50:1013-1016

24. American Psychiatric Association: Diagnostic and statistical manual of mental disorders DSM-IV 4th edition. Washington, DC: American Psychiatric Association; 1994.

25. Spady DW, Saunders DL, Schopflocher DP, Svenson LW: Patterns of injury in children: a population-based approach. Pediatrics 2004, I | 3:522-529.

26. Dykman RA, Ackerman PT: Attention deficit disorder and specific reading disability: separate but often overlapping disorders. J Learn Disabil I99I, 24:96-I03.

27. Semrud-Clikeman M, Biederman J, Sprich-Buckminster S, Lehman BK, Faraone SV, Norman D: Comorbidity between ADDH and learning disability: a review and report in a clinically referred sample. J Am Acad Child Adolesc Psychiatry 1992, 3 I:439-448.

\section{Pre-publication history}

The pre-publication history for this paper can be accessed here:

http://www.biomedcentral.com/1471-2431/5/34/prepub
Publish with Biomed Central and every scientist can read your work free of charge

"BioMed Central will be the most significant development for disseminating the results of biomedical research in our lifetime. "

Sir Paul Nurse, Cancer Research UK

Your research papers will be:

- available free of charge to the entire biomedical community

- peer reviewed and published immediately upon acceptance

- cited in PubMed and archived on PubMed Central

- yours - you keep the copyright
BioMedcentral 